\title{
TEORIAS PEDAGÓGICAS EMERGENTES E PREDOMINANTES NO BRASIL: UM ENFOQUE HISTÓRICO-CRÍTICO NA FORMAÇÃO DE PROFESSORES
}

\author{
Marcelo Manoel de Sousa
}

Mestre em Educação pela Universidade do Vale do Sapucaí - UNIVAS/MG. Docente da Universidade Federal do Piauí UFPI. E-mail: manoelsousa1985@bol.com.br

\section{RESUMO}

O objetivo deste trabalho é contribuir com a discussão sobre as teorias pedagógicas emergentes no Brasil e suas contribuições à prática educativa. As teorias da educação são consideradas fundamentos basilares na construção das práticas educativas, por isso constituem-se objeto de estudo constante. Observou-se que nenhuma prática pedagógica acontece à margem de um sistema teórico/prático norteador de formas e conteúdo. Além disso, haveria mais condições de se solucionar os muitos problemas assentados no contexto escolar se os professores soubessem em que se fundam os princípios e modos de ensinar em suas ações docentes. Sendo assim, é nesse contexto que as teorias da educação precisam ser tomadas como campo específico de conhecimento da formação de professores. Enfatiza-se, ainda, que o educador precisa optar politicamente para que sua prática não seja distorcida, e se imponha como elemento eficaz na formação de cidadãos. Este estudo utilizou-se da pesquisa bibliográfica como pré-requisito para investigar com profundidade, rigorosidade e globalmente o tema proposto. Promoveu-se, de modo abrangente, a análise da obra de Saviani, com a finalidade de fundamentar as ideias e posições teóricas expressas nos resultados da pesquisa. Cabe salientar que esta investigação integra uma pesquisa mais ampla que resultou em dissertação de Mestrado, defendida na área da Educação. Houve no espaço brasileiro a emergência, por vezes, de teorias pedagógicas, porém, sem considerarem os saberes científicos, filosóficos, estéticos na formação de todos e cada um. A perspectiva da Pedagogia Histórico-Crítica explicita este interesse. Por isso mesmo é considerada mais adequada á formação do cidadão brasileiro, principalmente das camadas menos favorecidas. Espera-se que seus resultados alcancem as práticas inovadoras de professores de todos os níveis, especialmente aqueles da escola básica, que poderão contribuir com pesquisas nesse sentido, orientadas ao conhecimento e significado dos estudos das teorias da educação.

Palavras-chave: Teorias da Educação. Formação de Professores. Prática Pedagógica.

\section{EMERGING AND PREDOMINANT PEDAGOGICAL THEORIES IN BRAZIL: A HISTORICAL-CRITICAL APPROACH TO TEACHER TRAINING}

\section{ABSTRACT}

The objective of this work is to contribute with the discussion about the emerging pedagogical theories in Brazil and their contributions to the educational practice. Theories of education are considered basic foundations in the construction of educational practices, so they constitute the object of constant study. It was observed that no pedagogical practice happens on the margins of a theoretical / practical system guiding forms and content. In addition, there would be more room for solving the many problems set in the school context if teachers knew where the principles and ways of teaching in their teaching were founded. Thus, it is in this context that theories of education need to be taken as a specific field of knowledge of teacher training. It is also emphasized that the educator must choose politically so that his practice is not distorted, and it imposes itself as an effective element in the formation of citizens. This study used the bibliographic research as a prerequisite to investigate with depth, rigor and globally the proposed theme. Saviani's work was extensively promoted, in order to substantiate the ideas and theoretical positions expressed in the research results. It should be noted that this research integrates a broader research that resulted in a master's thesis, defended in the area of Education. There was in the Brazilian space the emergence, at times, of pedagogical theories, however, without considering the scientific, philosophical, aesthetic knowledge in the formation of each and every one. The perspective of Historical-Critical Pedagogy makes this interest explicit. For this reason, it is considered more appropriate for the Brazilian citizen's 
education, especially of the less favored classes. It is hoped that their results will reach the innovative practices of teachers at all levels, especially those in the basic school, who may contribute to research in this direction, oriented to the knowledge and meaning of studies of educational theories.

Keywords: Theories of Education. Teacher training. Pedagogical Practice.

\section{NOTAS INTRODUTÓRIAS}

Os estudos das teorias da educação têm sua importância na medida em que fundamentam as práticas pedagógicas. No espaço brasileiro, emergiram e se fizeram hegemônicas a Pedagogia Tradicional, a Pedagogia da Escola Nova e a Pedagogia Tecnicista ou Reprodutivista das condições de produção de vida capitalista. Nessa perspectiva, pretende-se refletir, no sentido savianiano da palavra, empreendendo análise aprofundada, com rigorosidade e amplitude no estudo das referidas correntes de pensamento educacional no espaço brasileiro.

Este estudo se justifica, ainda, pela importância que deve ser dada às análises do atual pensamento hegemônico do sistema educacional no Brasil. A supramencionada teoria tecnicista, por ser uma corrente teórico/pedagógica interessada em organizar a escola conforme os galpões industriais, precisa ser posta em perspectiva crítica no sentido de transformação de seus processos. A escola, configurada por esta vertente, passa a ser um espaço em que o ser humano não encontra lugar de se manifestar, considerando a escola como ambiente privilegiado à formação de uma espécie de segunda natureza.

Portanto, a pesquisa enveredada, em face de seus resultados, é mais uma evidência da necessidade de se promover estudos que abordem a problemática em que se encontra a educação brasileira, diante de um processo burocrático, que aliena os indivíduos, robotizando os processos de ensino/aprendizagem, consequentemente, influenciando posturas falsas dentro da escola, como a neutralidade, a racionalidade, entre outras, características não condizentes com a especificidade dos processos que envolvem formação e humanidade nos indivíduos em sua historicidade.

Nessa linha de pensamento, utilizou-se de pesquisa bibliográfica que, segundo Severino (2007),é realizada por meio de publicações disponíveis em acervo já produzido por outros pesquisadores. Neste mesmo sentido, de acordo com Lakatos e Marconi (2013), a pesquisa bibliográfica é a que se empreende por via de materiais secundários, desse modo, os dados podem constar em revistas, jornais, livros, artigos entre outros veículos divulgadores de resultados de pesquisa científica.

O estudo teve como premissa contribuir com a discussão a respeito das teorias pedagógicas e suas contribuições à prática educativa das escolas da educação básica e de modo geral do ensino superior.

\section{O PENSAMENTO PEDAGÓGICO TRADICIONAL NO ESPAÇO BRASILEIRO (1549-1932)}

$\mathrm{Na}$ Pedagogia Tradicional, o professor era o dono do saber, nesse sentido, os alunos passivamente buscavam assimilar os conteúdos trazidos exclusivamente pelo professor que, auxiliado por outros alunos mais adiantados no conteúdo, desenvolvia suas aulas. Estas aulas, inicialmente, eram trabalhadas de uma perspectiva considerada por Saviani (2013b), como Pedagogia Brasílica - que vigorou de 1549 a 1599 -, bem característica dos modos de vida do recém-descoberto espaço brasileiro. Pode-se dizer que, nesse interregno, não havia um plano geral de estudos em que se pudesse apoiar as atividades pedagógicas dos jesuítas.

Os jesuítas desembarcaram aqui, pela primeira vez, com seu objetivo determinado de difusão do modo religioso cultivado pela então capital portuguesa. Conforme Saviani (2012, 2013b), quando a esquadra de Pedro Alvares Cabral desembarcou neste lado do Atlântico, encontrou um povo que vivia há muito tempo em comunidades, que mais se aproximava do comunismo primitivo. Indivíduos que sobreviviam da caça e cultivos de grãos, como milho, entre outros. Eram comunidades sem classes, por isso mesmo desenvolveram uma espécie de economia natural, apenas de subsistência.

Pode-se inferir, com base nessas informações, que a produção era organizada de forma coletiva, não havendo repartição por classes dos bens adquiridos. A educação, neste 
contexto, era orientada de modo prático, tal que se confundia com as vivências cotidianas. Os ensinamentos eram transmitidos dos mais velhos para os mais jovens e assim, sucessivamente, assim, a cultura não desfalecia. "De modo geral, [...] os conhecimentos e técnicas sociais eram acessíveis a todos, não se notando qualquer forma de monopólio. A cultura transmitia-se por processos diretos, oralmente, por meio de contatos primários no interior da vida cotidiana" (SAVIANI, 2013b, p. 38). Esse contexto indica claramente que os modos de produção inicial do conhecimento abrangiam a todos, sem exceção, pois era de interesse da totalidade dos indivíduos.

O modo aparentemente simples de organização social dos primeiros povos habitantes do Brasil recebeu altas doses de alterações a partir da chegada dos colonizadores portugueses, portando sua bagagem, seus hábitos e cultura próprios. Neste sentido, as ordens religiosas aparecem como instrumentos viabilizadores da eficácia do projeto colonizador da metrópole. Estas ordens funcionaram muito bem, com o pretexto de catequizar os povos conquistados, efetivaram, concomitantemente, os interesses do colonizador.

É nesse sentido que Saviani (2013b, p. 39), categoricamente, afirma que: "a colonização do Brasil contou com a contribuição imprescindível das ordens religiosas", e acrescenta que se "pode considerar que os primeiros evangelizadores do Brasil foram os franciscanos"(2013b, p.39). Afora outras ordens, a mencionada chegou aqui em número de oito franciscanos abordo da caravela de Pedro Alvares Cabral, em meados de 26 de abril de 1500 , celebrando a primeira missa, pelo frei Henrique de Coimbra, porém, logo em 2 de maio, partiram novamente na frota de Cabral. É importante mencionar esta experiência, por se transformar em marco que deu início aos trabalhos catequistas dos colonizadores.

Todavia, como já adiantado, no Brasil, a educação iniciou-se, do ponto de vista dos jesuítas, com um platô de estudos elaborado por Manuel da Nóbrega, denominado por Saviani (2012, 2013b) de Pedagogia Brasílica. Nóbrega, homem de espírito empreendedor, objetivara disseminar sua pedagogia, com efeito, sobre uma extensa cadeia de colégios construídos ao longo da margem das populações litorâneas. Assim, como pontos cardiais, estariam, na região Norte, o colégio da Bahia e, do outro lado, na região Sul, o colégio de São Vicente. Não obstante, as experiências levadas a efeito no vetor relacionado às primeiras tentativas de aculturalizar as populações das terras recémdescobertas, o trecho a seguir ilustra muito bem.

A primeira fase da
educação jesuíta foi
marcada pelo plano de
instrução elaborado por
Nóbrega. O plano iniciava-
se com o aprendizado do
português (para os
indígenas); prosseguia
com a doutrina cristã, a
escola de ler e escrever e,
opcionalmente, canto
orfeônico er música
instrumental; e culminava,
de um lado, com o
aprendizado profissional e
agrícola e, de outro lado,
com a gramática latina
para aqueles que se
destinavam à realização de
estudos superiores na
Europa (Universidade de
Coimbra).Esse plano não
deixava de conter uma
preocupação realista,
procurando levar em
conta as condições
específicas da colônia.
(SAVIANI, 2013b, p. 43).

Conforme este plano de estudos, verificase que a educação proposta, ou melhor, o ensino levado a efeito, neste caso, revelava certo elitismo em sua estrutura de ensino. Aqueles que supostamente se interessavam pela continuidade dos estudos poderiam dar prosseguimento na famosa Universidade de Coimbra, localizada na sede de Portugal. Este fato, aqui e ali, mencionado, visava formar novas gerações de padres comprometidos com a causa colonizadora dos ideais religiosos expressos nos interesses da Companhia de Jesus, instituição idealizada pelo padre Inácio de Loyola.

Porém, como evidencia Saviani (2012), Manuel da Nóbrega ousou elaborar uma pedagogia propícia ao regionalismo do território brasileiro, isto é, como observa o próprio autor, era um plano que resguarda em si certo realismo. Isto porque considerava, em seu interior, peculiaridades características do modo de vida da população aqui existente. Estas colocações se atestam, em especial, no modo de produção de 
existência dos indígenas. Assim, conforme Saviani (2012, 2013b), Loyola prezou por instruir seus discípulos para além dos conteúdos das gramáticas, abordando também os que se destinavam ao desenvolvimento do projeto colonizador e aos que produziriam os meios de subsistência materiais, os afazeres práticos, como o cultivo agrícola e profissionalizante. Dividem-se, então, as tarefas conforme a destinação de classe de cada segmento social de produção.

Chama a atenção o fato de esse intento ter sido desaprovado pelo núcleo organizador das missões jesuíticas, ou seja, a Companhia de Jesus, causando discussões interna. Considerando essa situação, as iniciativas dos esforços de Loyola não puderam ir adiante por muito tempo, evento que apesar de seus auspícios, em termos de considerar a realidade do território em processo de colonização, "sua aplicação foi precária, tendo cedo encontrado oposição no interior da própria Ordem jesuítica, sendo finalmente suplantado pelo plano geral de estudos organizados pela Companhia de Jesus e consubstanciado" no plano geral designado Ratio Studiorum (SAVIANI, 2013b, p. 43).

Em suma, a partir de 1599, são dadas por finalizadas as iniciativas parciais levadas a efeito por Loyola. Marco este que ensejou um novo momento para que as ideias pedagógicas se fizessem aparecer no contexto do reinado da coroa portuguesa, por meio de bases e princípios totalmente religiosos, pelas mãos da Ordem da Companhia de Jesus. Como é sabido, a Pedagogia Tradicional foi marcadamente dividida em dois momentos fundamentais. Assim, como não se pode creditar a existência das ideias pedagógicas propriamente ditas até o referido ano, do supracitado plano até 1759 , a Ratio Studiorum se propaga sendo dominante em seus pressupostos em todo território português. Porém, a partir dessa data, os jesuítas começaram a ser vistos como indivíduos que se desviaram de suas precípuas funções - propagar a fé católica -e se enveredaram a juntar riquezas, constituir patrimônio, terras, escravos; situação que desagradou imediatamente à coroa.

Neste momento, instala-se no cenário brasileiro a figura do Marquês de Pombal, então ministro da corte, que objetivou expulsar os jesuítas de todo o território do reinado português. Nesse caso, buscou implantar as chamadas aulas régias, voltadas para a valorização das ciências, influenciadas pelo movimento iluminista. Este acontecimento foi alvo de severas críticas pelo fato de ter descontinuado certo sistema educacional já implantado e com suas raízes profundas. Isto é, após a expulsão dos jesuítas, não se tinha um plano mais sistemático de educação, por esta razão, embora se acredite que era necessário valorizar as ciências nos processos de ensino/aprendizagem, discorda-se que não tenha sido implantado um sistema mais coerente e orgânico, em detrimento dos esforços empreendidos pelos jesuítas.

Contudo, os estudos referentes às aulas régias diziam respeito ao ensino das ciências, mas num contexto bastante arraigado pelas ideias religiosas, considerando-se que, em Portugal, havia fortíssima influência das ordens religiosas nos rumos da política do reinado. O trecho a seguir expõe, exatamente, sobre esse momento de inovação ideológico-educacional.

O século XVIII foi marcado, em Portugal, pelo contraste entre a atmosfera religiosa, ainda dominante, com seu séquito de crendices, e a visão racionalista pautada pela lógica; entre o anseio por mudanças e o peso das tradições; entre fé e ciência. A penetração das novas ideias, de influência iluminista, dava-se especialmente a partir de portugueses residentes no exterior como Dom Luis da Cunha, Luis Antônio Verney, Alexandre de Gusmão e o próprio Sebastião José de Carvalho e Melo, que viria a ser o Marquês de Pombal. (SAVIANI, 2013b, p. 77).

Como atesta o excerto supracitado, as ideias pedagógicas se instalaram no Brasil por meio das influências de padres e autores que se identificavam com as novas ideias. Portanto, o pensamento pedagógico do Brasil, que se veiculou com as iniciativas das reformulações do Marquês de Pombal, se encontrava eivado de desígnios religiosos e científicos. Pode-se inferir, então, que havia um ecletismo de ideias sendo operadas no pensamento educacional da política endereçada a todas as colônias portuguesas, inclusive ao Brasil.

Importante acrescentar, porém, que o ideário pombalino perdurou por todo período 
atribuído à Pedagogia Tradicional. Entende-se que, mesmo com as tentativas da inserção das ciências no preparo escolar dos indivíduos no referido tempo, não logrou êxito, pelo menos em termos de consolidar um sistema educacional, mas tão somente experiências isoladas, as quais, intermitentemente, se modificavam sem maiores efetividades. Neste contexto, buscou-se estabelecer um ensino leigo, mas sem conseguir hegemonia, pois, como já indicado, havia a predominância do ecletismo de ideias inserido nas decisões políticas da capital. Considerando esta contextura de ideias e experiências, pode-se afirmar que, somente a partir de 1932, com o Manifesto dos Pioneiros da Educação Nova, houve alteração em todo esse quadro e, por vezes, conquistam espaço cada vez mais abrangente os estudos fundamentados nas ciências.

\section{O IDEÁRIO DA ESCOLA NOVA E SUAS PRÁTICAS NO CONTEXTO BRASILEIRO (1932-1969)}

Logo no final do século XIX esboça-se, em termos gerais, uma nova forma de pensar a educação e seus processos de ensino/aprendizagem. Esta corrente pedagógica denominada Pedagogia da Escola Nova alastrouse pelos territórios direcionando o ideário educacional das práticas de ensino. Por conseguinte, esta nova forma de conceber a Pedagogia, objetiva colocar em evidência, no centro dos processos, outro sujeito como agente dos expedientes educacionais - o aluno. Nesta nova fase da produção pedagógica, o professor se polariza com intercâmbios quase que antagônicos com o educando, isto é, em lados opostos se encontram professor e aluno, sobrepondo-se de modo desigual na relação de ensino/aprendizagem.

Com efeito, o professor se torna apenas expectador da vontade e dos interesses do aluno, exercendo um papel indireto nos processos educativos. Situação esta que, segundo Saviani $(2009,2012)$ manteve certo padrão de qualidade de interesse da classe dominante, porém, em relação ao ensino e à aprendizagem da classe trabalhadora, não obteve sucesso. Isto ocorreu em virtude do altíssimo encargo atribuído à nova Pedagogia, ainda por corresponder a uma nova estrutura, um novo modo de organizar a escola e seus procedimentos de aquisição dos conteúdos escolares. Por esse motivo, alastrou-se de modo apenas ideológico-teórico, mas, na prática, os professores da escola popular não puderam e nem podem fazer muito, no sentido de colocar em prática os pressupostos de uma Pedagogia Nova, exatamente pela carência estrutural.

Os condicionantes socioeconômicos e materiais se fizeram determinantes para que o escolanovismo fosse praticado apenas em algumas zonas, nas quais o desenvolvimento se fez mais efetivo, por isso mesmo elitista, e não obstante uma Pedagogia corporativista. Nesse contexto, se a Pedagogia Tradicional manteve o foco no ensino, a Pedagogia Nova buscou orientar-se pela produção da aprendizagem como preocupação precípua de seus horizontes.

Essa Pedagogia nasce a partir do reconhecimento das etapas do desenvolvimento humano em relação aos processos educativos. Há pesquisadores da educação que citam Rousseau como o primeiro pensador educacional inserindo - aluno como centro dos processos de ensino/aprendizagem. Dessa feita, altera-se o lugar de destaque dado ao professor na Pedagogia Tradicional, para enfatizar que a educação deve estar em volta do desenvolvimento do educando.

No Brasil, a Pedagogia Produtivista, expressão mais à maneira de Saviani $(2009,2012$, 2013b), surge em 1932, com o Manifesto dos Pioneiros da Educação, assinado por Anísio Teixeira, Lourenço Filho, entre outros educadores brasileiros importantes. Foi então por meio desta carta, amplamente divulgada em todo o território nacional, que se alastrou o ideário da Escola Nova, projetando-se no centro das escolas formadoras da elite, e mais escassamente nas escolas populares.

Conforme Saviani (2012) desloca-se o sentido do como ensinar, focado no professor, para o como se aprende, ligado ao aluno e aos processos mediadores da relação educador/educando. Segundo o referido autor, esse acontecimento estabeleceu um novo paradigma no universo das práticas educativas. $O$ aluno passou a ser o elemento principal dos processos educativos, tendo o professor como mero guia da aprendizagem. Posição bastante criticada, pois, ainda de acordo com o autor, esvaziou-se de conteúdos os processos educacionais, quando enfatizou os procedimentos metodológicos em detrimento dos conteúdos a serem assimilados. Mais a forma e menos o conteúdo.

Contudo, houve pontos positivos emergentes a partir do desenvolvimento da Escola Nova, como se pode atestar pelo desfecho 
que se deu à descoberta da individualidade; do esforço em tratar com especificidade as características educacionais do modo de aprender conforme as diferenças reais dos indivíduos. Entre outros fatores importantes, cabe salientar que o escolanovismo deslocou os processos da lógica formal, isto é, abandonou a lógica do objeto em detrimento da lógica do sujeito, considerando as reais necessidades individuais do modo de aprender de cada um. Isto, por consequência, implicou na forma como se organizou a escola, a formação do professor e o multicolorido ambiental, objetivando captar o interesse do ensino/aprendizagem na diversidade.

Ainda se pode somar a esses pontos favoráveis a realização científica dos programas educacionais. Assim, foi por intermédio do escolanovismo que se conferiu ênfase aos fundamentos científicos da educação, para efeito de melhor racionalizar o desenrolar do ensino e da aprendizagem, visando atingir determinados objetivos. Neste sentido, como a Pedagogia ainda se encontrava em lenta produção científica, isto é, a Pedagogia até o século XVII se encontrava subsumida literalmente no campo da filosofia (GAUTHIER, 2010), e somente após Rousseau, Comênio, Herbart, entre outros pensadores da educação, foi que se começou a efetivar elaborações mais sistematizadoras de uma Pedagogia "positiva", com vistas a controlar racionalmente o modo como se processava a aprendizagem, considerando a real complexidade dos processos envolvidos na esteira do desenvolvimento da aprendizagem.

Esta Pedagogia esteve em desenvolvimento e paralelamente disputando a hegemonia com a Pedagogia Tradicional, até 1947, que após longos debates e circunstâncias sócio-históricas e econômicas veio a dominar os processos educacionais, como já salientado, com menos ênfase nas escolas públicas, pelo menos em sentido concreto. Entretanto, segundo Saviani (2012), estas ideias permeiam o pensamento dos professores, mas sem muita chance de se tornarem algo praticado efetivamente, pois careceria reestruturar todo o sistema educacional, ação impraticável diante das circunstâncias históricas que envolvem a escolarização popular.

Apesar de sua conspicuidade inerente, deu-se relevo às características científicas do campo da educação/Pedagogia, algo que assegurou e desenvolveu a confirmação da educabilidade do ser humano por meio de planificações, conforme as necessidades humanas; isto é, se a Pedagogia era pensada antes pelo viés filosófico, desligou-se desta mediante a possibilidade projetiva de uma nova ciência entre outras ciências já consagradas; que poderia, mediante métodos e princípios próprios, desenvolver suas pesquisas e análises da realidade educacional e, sobretudo, ao que acontece no vetor que anexa de um lado o professor e de outro o aluno.

Os métodos e as técnicas desenvolvidos no centro da Pedagogia Nova e postos à disposição dos eventos de aprendizagem facilitaram a emergência de outra corrente de pensamento que, a partir da década de 1950 e 1960, foi se delineando conforme adquiria cada vez mais vulto num contexto em que se dava importância fundamental aos interesses da produção econômica da educação. Com isso, revelou-se, por meio da teoria do capital humano, o papel da educação para o desenvolvimento industrial, experiência pela qual estava passando o Brasil, quando saía de uma forma econômica agrária atrelando-se, paulatinamente, ao fluxo internacional do movimento industrial.

De fato, a globalização tomou de conta dos países em desenvolvimento como é o caso do Brasil e, nesse enquadro, a educação foi considerada como elemento-força no empreendimento que se desenvolvia de modo acelerado, envolvendo todos os setores produtivos, inclusive o educativo. Portanto, nessa interconexão de experiências, arraigada pelo movimento de industrialização, abriu-se espaço para pensar a Pedagogia designada como Tecnicista ou Produtivista.

\section{ORIGEM E DESTINO DA PEDAGOGIA TECNICISTA OU PRODUTIVISTA (1969-PREDOMINANTE)}

De acordo com Saviani (2012), essa teoria pedagógica nasce da dimensão econômica dos processos educativos. Experiência que Libâneo (2010) acrescenta, enfatizando, que esta corrente se originou do centro da Escola Nova, isto é, à medida que esta escola confere aos processos metodológicos maior ênfase em detrimento dos conteúdos científicos e culturais, permite o aparecimento e o fortalecimento de uma nova linha de pensamento pedagógica.

Nesse sentido, acrescenta um fator anterior, ou seja, a partir da década de 1950 desenvolve-se um despertar de acúmulo de 
capital por meio da instrução escolar. Neste contexto, nem o professor, nem aluno tem voz e vez. Retira-se toda a autoridade do educador, e o aluno passa a ser apenas uma futura peça de um sistema que funciona mediado pela lei da procura/oferta.

Sendo assim, acredita-se que a excelência educativa se efetiva racionalizando os meios de produção do conhecimento perante os processos de escolarização. Observa-se que, se na Pedagogia Tradicional o principal agente era o professor; na Pedagogia Nova o aluno/educando, na Teoria Produtivista da Educação eleva-se a funcionalidade dos meios organizacionais e operadores dos processos pedagógicos como elementos-chave do ordenamento dos programas instrutivos.

Com base nessa orientação, pode-se acrescer certos impasses, os quais causaram mais problemas que resoluções, conforme os interesses da escolarização popular. Na medida em que se faz a transposição dos esquemas empresariais para o âmbito da escola, algo totalmente inconveniente, do ponto de vista da real natureza da formação humana, papel claramente esperado da escola. Nesse caso, como valorizar a formação pessoal indo além da instrução profissional dos sujeitos? Nessa estrutura de pensamento educativo, parece improvável conciliar estas duas dimensões, visto que a existência de avareza é evidente. Se não é isso, então será que é possível observar o problema da formação para o indivíduo e concomitantemente para o Estado?

O questionamento acima sugere aprofundamento da relação indivíduocoletivo/Estado. A esse respeito pode-se pensar o seguinte: a partir do momento em que foram instalados na escola os mesmos processos de produção da máquina industrial, torna-se impossível pensar que o mencionado contexto possa contemplar uma educação interrelacional indivíduo-coletivo/Estado. Esta reflexão do problema leva irrevogavelmente a se lembrar dos princípios que regem um sistema e outro: empresa/escola. Os princípios de racionalidade, neutralidade, eficiência, eficácia, não duplicação de meios para fins idênticos dão mostras de que formar o(a) cidadão(ã) é algo impossível por esta perspectiva, lembrando que o ser humano é uma entidade por demais complexa, consequentemente, não se encaixaria em esquemas rígidos como pretende a teoria tecnicista, hospedada nos sistemas escolares no século XXI.

Porém, apesar de seu insistente desenvolvimento e manutenção, devorando e fazendo desaparecer a parte humanizante da escola, críticas e análises de seu conteúdo e interesses têm sido empreendidas, ainda na década de 1970, pelas correntes que Saviani (1994, 2013b) nomeou de crítico-reprodutivistas. Neste sentido, o tecnicismo sofreu ataques virulentos, especialmente da teoria do "sistema de ensino como violência simbólica", elaborada pelos teóricos Bourdieu Passeron (1970), os quais construíram o pensamento da obra se orientando pela análise dos condicionantes sociais bloqueadores dos anseios da natureza própria da educação. Por esta razão, esses autores observaram a escola como lugar de reprodução ideológica do pensamento dominante.

Contudo, não só esta corrente de pensamento se orientou no sentido da crítica ao tecnicismo produtivista elaborado e desenvolvido pelo sistema capitalista, mas também se une a esse esforço Althusser (1969), em seu artigo intitulado "A escola como aparelho ideológico de Estado", no qual assevera que a escola nada mais é que um subsistema reprodutor dos interesses concretos do Estado, o qual, por conseguinte, favorece a dominação por meio dos processos de ensino e aprendizagem dos indivíduos; portanto aparelho que permite reproduzir livremente a ideologia da classe dominante pelos processos escolares.

A estas duas vertentes soma-se a "teoria da Escola dualista", desenvolvida por Baudelot e Establet (1971), a qual, em essência, visa atingir o mesmo objetivo que as outras duas linhas de pensamento explanadas acima. Portanto, a Escola também, nesta teoria, é vista como reprodutora da ideologia dominante aos dominados, porém, acrescenta-se uma particularidade fundamental: esta minudência seria o reconhecimento da ideologia dominante de uma específica ideologia contra-hegemônica, produzida pela massa trabalhadora, a qual convive in loco do espaço escolar em paralelo com a dominante.

A ressalva que se faz a este imbróglio é que a ideologia dominante faz uso de sua energia para recalcar os interesses dos dominados, pois, mesmo reconhecendo que a classe popular elabora fora da Escola sua ideologia, esta não pode vir a ser dominante, por isso os próprios autores consideram a Escola como dualista. 
O problema é que estas análises do sistema capitalista, que empreende atividades tecnicistas nos sistemas escolares, não anunciou uma Pedagogia como alternativa. Embora se reconheça que as mencionadas teorias nunca tiveram tal objetivo, por isso não resolveram o problema, mas tão-somente auxiliaram com suas categorias a compreender a relação Escola/sociedade. Assim, inicialmente, o que parecia uma opção se tornou um motivo de desalento aos professores.

Acredita-se que uma parcela de desânimo alojado no pensamento de muitos educadores se encontra aninhada neste aspecto da história das ideias pedagógicas. Por certo, consoante à produção das análises explicativas, da realidade escolar com base nas elaborações apontadas, não poderia ser possível relacionar o antigo interesse de mudança pela Escola. Esta realização ficou impraticável perante as teorias críticoprodutivistas, posto que, de todas as formas, a ideologia dominante ganharia todas as apostas.

Mas, o anseio por uma saída persistia, até que a partir da década 1980, conforme documenta Saviani (1994), começou-se a esboçar a teoria Histórico-Crítica que, no interstício do sentimento de ilusão de poder à derrocada desse ânimo, forjou a possiblidade de superação da Escola como especificamente reprodutora da concepção dominante tecnicista da educação. Diante dessa necessidade, a escola pôde ser reinserida em seu lugar natural, e os processos envolvidos com o problema do ensino e da aprendizagem puderam ser conjugados dentro de uma perspectiva dialética.

\section{EM DEFESA DA PEDAGOGIA HISTÓRICO-CRÍTICA NO CONTEXTO DA ESCOLA PÚBLICA}

A história da existência da Pedagogia Histórico-Crítica inicia-se, segundo Saviani (1994), no enquadro de seus estudos e análises do reprodutivismo da escola. Fato ocorrido com base na produção de autores que objetivaram elaborar a crítica da escola valendo-se das circunstâncias ocorridas em 1968. Marco esse que culminou com o fracasso do movimento estudantil. Sumariamente, pode-se expor que grupos de alunos e professores, na data indicada, arquitetaram reformar a sociedade pela via da reforma cultural.

Não obstante, diante do referido evento, surgiram críticas direcionadas à impossibilidade de reformar a sociedade vigente pelas forças empreendidas pelos grupos estudantis, que se desenrolou na França e difundiu-se pelos vários países europeus, em especial no Brasil. De acordo com Saviani (1994), a diferença é que aqui teve o componente conspícuo da força policial. Sublinha-se, de passagem, porém, que o Brasil de 1968 estava submerso no regime políticoditatorial. Clima, portanto, desfavorável à aceitação de revoluções reivindicatórias por parte dos interesses concretos de reformas gerais.

Nessas circunstâncias, a produção que iam fazendo da referida conjuntura, conjugava suas análises pelo vetor escola e sociedade. 0 que Saviani (1994) observa, nesta produção, que buscava fazer uma crítica da sociedade vigente, é exatamente que, para os reprodutivistas, não podia uma revolução cultural empreitar a superação das relações vigentes. Esse pensamento funda-se no princípio de que a cultura também é ideológica e faz parte da estrutura que sustenta a sociedade e tudo que há sobre sua plataforma. Surge, dessa maneira, certo pessimismo pedagógico. Se a escola é reprodutora das relações sociais vigentes, e não há possibilidade de uma prática crítica transformadora, o que fazer? Questionamento possível, parafraseando o pensamento dos professores, como desespero causado pelas interpretações surgidas naquele contexto. Finalmente, a Pedagogia Histórico-Crítica emerge, nesse âmbito de questionamentos e saídas quase que intransponíveis, como uma prática pedagógica crítica, que não fosse reprodutora.

Esta Pedagogia surge, conforme Saviani (1994), na década de 1979, com o interesse em sistematizar os processos pedagógicos fragmentados no seio das teorias referidas anteriormente. Nesta Pedagogia contrahegemônica, os agentes dos processos da educação são professores e alunos, mediatizados pelos conteúdos, pelas ciências e pela cultura de modo geral.

Para o autor supracitado e criador da Pedagogia ora em análise, as correntes pedagógicas, por vezes, conferiram ênfase à filosofia da educação, ou aos princípios oriundos desta, a outras, como a teoria da educação ou Pedagogia, quando não se deu importância às práticas pedagógicas. Contudo, segundo Gasparin (2012), a Pedagogia Histórico-Crítica sistematizou seu método de ensino-aprendizagem de modo que todos esses elementos pudessem ser organizados em um sistema - uma Pedagogia em sentido estrito -, já que para Saviani (2012), uma teoria da educação só pode ser considerada 
como tal se estiver voltada para desenvolver as práticas da formação humana.

Destarte, a Pedagogia Histórico-Crítica, com interesse na instrução da classe menos favorecida, pode ser desenvolvida considerando a prática social global como ponto de partida. Em seguida, problematizam-se as experiências vividas pelos agentes dos processos educativos educadoreducando. $O$ terceiro passo é a instrumentação dos educandos, numa relação em que todos aprendem e pesquisam os problemas pertinentes, pois, nesta concepção, o conhecimento é inacabado, devendo ser reconstruído constantemente.

O quarto passo é a catarse, momento em que se busca elaborar resoluções para os problemas apontados como basilares, mas com base na ciência e cultura elaborada, em relação ao passo inicial com o professor agente de uma síntese precária, e o aluno com seu repertório de vivências espontâneo. $\mathrm{O}$ quinto e último passo é a prática social final, marco em que os educandos, agora munidos de uma cultura sistematizada, se encontram em situação de enfrentamento dos problemas trabalhados desde o início, com mais eficácia e sucesso. Enfatiza-se que estes momentos não se dão dentro de processos lineares, todavia, enreda-se de modo complexo/dinâmico em que se interconexa as práticas sociais e atividades educativas/formativas.

O que se pode perceber, portanto, é que esta teoria - que fez frente à Pedagogia Tecnicista ou Produtivista, desenvolvida conforme os interesses da educação enquanto valor econômico - é, de fato, uma visão de educação que veio auxiliar as práticas educativas, não de modo otimista, porque compreende os limites concretos impostos pela estrutura social vigente. Impõe-se, neste contexto, que os professores se esforcem por meio da análise crítica e reflexiva de seu fazer cotidiano dentro das salas de aula.

Esta reflexão sugerida, não é qualquer reflexão, conceito tido como desgastado e simplista do ponto de vista do senso comum e bastante difundido na literatura educacional e espaços escolares, pelo menos nos visitados pelo pesquisador deste estudo. Como bem assevera Saviani (2013a), é fundamental promover um pensamento filosófico a fim de superar o senso comum. Pensamento compartilhado pelo pesquisador, pois acredita ser relevante para 0 educador começar por se esforçar a sair do engodo do cotidiano, é preciso ver as possibilidades de atendimento das reais necessidades dos processos ensino/aprendizagem. É dessa maneira que se acredita que a Escola poderá cumprir seu papel diante dos interesses da formação do ser humano que, com muita dificuldade, adentra em seu espaço.

$\mathrm{Na}$ obra supramencionada, o autor assinala que é preciso refletir considerando três fatores de extrema importância, não sendo assim, cai-se na "cantada da sereia", a saber: é preciso harmonizar um pensamento radical, rigoroso e globalizante, somente dessa forma se pode alcançar a compreensão concreta dos problemas que se vão impondo ao trabalho escolar. Acredita-se que este modo de encarar a realidade prática do ensino e da aprendizagem se faz necessário nos dias atuais. E sua importância está que, conforme o que se vem delineando, nota-se que o sistema de ensino brasileiro está passando por momentos críticos.

Esse estado crítico se apresenta exatamente pela via da tecnoburocratização da educação, provocando, de modo aprofundado, incoerência com o sentido específico da educação para a vida humana. Todavia, a educação tem como finalidade imprimir a humanidade em todos e em cada um dos indivíduos. Sendo assim, percebe-se que a educação limitada à tecnologia, dispensa o que mais a caracteriza enquanto dimensão humana.Com base nesse quadro, é fundamentalmente inconteste que a educação formativa do ser humano necessita ser resgatada do viés de robotização causado pela racionalidade técnica da realidade social vigente.

\section{NOTAS CONCLUSIVAS}

Contudo, considerando as teorias pedagógicas como elementos fundantes das práticas educativas, considerou-se que a compreensão de suas proposições e consequências na formação de professores pode acarretar em consequências negativas ou positivas à formação da classe trabalhadora.

Desse modo, entrar na discussão em que tem as correntes pedagógicas como principal objeto, é estar de algum modo engajado na busca do processo ensino/aprendizagem da melhor qualidade, em que todos e cada um possam se constituir como cidadã (o) contribuinte ao desenvolvimento individual de cada um e coletivo da sociedade. 
Assim, quando se referiu à teoria pedagógica tradicional, teve-se $\mathrm{o}$ intuito de esclarecer que seu conteúdo impossibilitou o desenvolvimento, historicamente, de práticas educativas em que fosse viável uma vivência rica em aprendizagem crítica, política, científica e cidadã, num espaço democrático.

Porém, com o aparecimento do escolanovismo no território brasileiro acreditouse que suas contribuições teriam o poder de sumir com os problemas educacionais de todos e cada um, quando na verdade não passou de uma pedagogia elitista disfarçada de antídoto à formação de uma nova geração societária. Esta vertente foi tão excludente quanto nefasta quando se inseriu nas escolas populares apenas em termos ideológicos, contudo sem os recursos materiais, que lhes expressavam a concreticidade. Enquanto nas escolas da classe dominante se posicionou adequadamente.

Por sua vez, surge de dentro desta teoria, a chamada Pedagogia Tecnicista, aquela que enfatizou absolutamente as técnicas/os meios de gerar aprendizagens, porém, colocando em segundo plano os conteúdos, os saberes científicos, filosóficos, estéticos, etc. esvaziando a formação da classe trabalhadora do essencial, os instrumentos advindos desses campos do conhecimento humano como requisitos de sobrevivência e luta contra as injustiças sociais. É neste sentido que se transformou inadequada como espada de luta da classe trabalhadora da sociedade brasileira. A qual almejou outra vertente teórico/prática de se pensar a formação humana: a Pedagogia Histórico-Crítica.

Em suma a realidade brasileira dos anos oitenta para cá, vem se configurando cada vez mais a produção de uma práxis denominada Pedagogia Histórico-Crítica alicerçando novos modos de fazer educação. Esta linha de pensamento revolucionário objetivo instrumentalizar as classes trabalhadoras do Brasil. Isto porque, até então não ocorreu neste espaço uma formação plena, crítica, abrangente, cultural e cidadã dos sujeitos imbricados nas práticas da produção material e culturais no Brasil. Portanto os trabalhadores os professores de todos os níveis precisam compreender esta proposta inovadora e cheia de possibilidades de formação em um contexto de práxis.

\section{REFERÊNCIAS}

GASPARIN, J. L. Uma didática para a pedagogia

histórico-crítica. 5. ed. Campinas: Autores
Associados, 2012. (Coleção educação contemporânea).

GAUTHIER, C. Da Pedagogia tradicional à pedagogia nova. In: GAUTHIER, C.; TARDIF, M. A pedagogia: teorias e práticas da Antiguidade aos nossos dias. Petrópolis: Vozes, 2010. p. 175-202.

LAKATOS, E. M.; MARCONI, M. A. Metodologia do trabalho científico: procedimentos básicos, pesquisa bibliográfica, projeto e relatório, publicações e trabalhos científicos.

7. ed. São Paulo: Atlas, 2013.

LIBÂNEO, J. C. Pedagogia e pedagogos, para quê? 12. ed. São Paulo: Cortez, 2010.

SAVIANI, D. A pedagogia no Brasil: história e teoria. 2. ed. Campinas: Autores Associados, 2012. (Coleção memória da educação).

SAVIANI, D. Educação: do senso comum à consciência filosófica. Campinas: Autores Associados, 2013a.

SAVIANI, D. Escola e democracia: teoria da educação, curvatura da vara, onze teses sobre a educação política. 41. ed. Campinas: Autores Associados, 2009.

SAVIANI, D. História das ideias pedagógicas no Brasil. 4. ed. Campinas: Autores Associados, 2013b. (Coleção memória da educação).

SAVIANI, D. Pedagogia Histórico-Crítica: primeiras aproximações. 4. ed. Campinas: Autores Associados, 1994.

SEVERINO, A. J. Metodologia do trabalho científico. 23. ed. São Paulo: Cortez, 2007.

Submetido em: 23/09/2018

Correções Obrigatórias: 21/11/2018

Aceite Final em: 17/12/2018 